\title{
Introduction to Practice Matters Special Section on VA Compensation and Pension Exams for PTSD and Other Mental Disorders
}

\author{
F. Barton Evans
}

Received: 4 September 2011 / Accepted: 8 October 2011/Published online: 22 December 2011

(C) Springer Science+Business Media, LLC (outside the USA) 2011

As Section Editor, it is with considerable pleasure that I introduce the Practice Matters Section of Psychological Injury and the Law (PIL). The brainchild of PIL Founding Editor-in-Chief Gerald Young, this section of the journal features articles focusing on practical applications of the science of psychological injury. The section concerns "on the ground issues," such as how to conduct examinations in such areas as disability law, police-related assessments, and workers compensation. It further plans to include new test reviews, how to use tests, and how to integrate developing case law and new professional guidelines into one's day-today psychological injury-related work. Consistent with the mission of PIL, articles will incorporate the scientific underpinnings fundamental to competent and ethical forensic psychological and psychiatric practice.

For its maiden voyage, the Practice Matters Section presents a Special Section of three articles on Department of Veterans Affairs (VA) Compensation and Pension (C\&P)

\footnotetext{
Author Note F. Barton Evans, Department of Veterans Affairs, Charles George VA Medical Center, Compensation \& Pension Program, Asheville, North Carolina

Notice: This article and the recommendations or opinions stated herein should in no way be construed to reflect the opinions or beliefs of the U.S. Department of Veterans Affairs or the United States government. The opinions expressed in this article are the author's alone.
}

F. B. Evans $(\bowtie)$

Charles George VA Medical Center,

Compensation \& Pension Program,

1100 Tunnel Road,

Asheville, NC 28805-2576, USA

e-mail: f.barton.evans@va.gov

F. B. Evans

Clinical Professor of Psychiatry and Behavioral Sciences,

George Washington University School of Medicine,

Washington, DC, USA examinations. While literally hundreds of these examinations are conducted on any given work day, to my knowledge, there has never been a comprehensive treatment published in a peer reviewed journal that describes how such examinations should be conducted in a manner consistent with standard forensic psychological and psychiatric practice. This Special Sections provides such an opportunity and hopefully opens serious discussion and debate on this area of professional practice.

The Special Sections opens with attorney and law professor James Ridgway's review of the history and legal foundation for VA C\&P PTSD and mental disorders examinations, emphasizing the vagaries and complexities of this disjointed area of psychological injury law. His cogent description and analysis presents $\mathrm{C} \& \mathrm{P}$ psychological and psychiatric practitioners with a much-needed legal basis for these examinations, providing legal information and guidance that is currently unavailable in a single resource.

Next comes the centerpiece of the Special Section, Worthen and Moering's practical guide for conducting C\&P PTSD and mental disorders examinations. The authors go into considerable detail about many aspects of these examinations, continually emphasizing a scientific and factual basis for psycholegal opinions central to good forensic psychological and psychiatric practice. For seasoned forensic psychological and psychiatric examiners, Worthen and Moering may seem quite basic at times. Please bear in mind that the current practice in C\&P examinations often involves a simple, unstructured interview followed by a psychological report with a psycholegal opinion frequently leading to lifetime financial award. Worthen and Moering acknowledge time and political pressures on C\&P PTSD and mental disorders examiners, though opt for a scientifically and factual based approach to these examinations. 
Indeed, a recent survey of mental health C\&P examiners by Jackson, Sinnott, Marx, et al. (2011) found that the examiners rarely use structured diagnostic interviews for PTSD, and only $12 \%$ of the examiners administer the MMPI-2. These statistics are especially intriguing given that the VA's Best Practice Manual for Posttraumatic Stress Disorder (PTSD) Compensation and Pension Examinations (Department of Veterans Affairs, 2002) specifically recommends using a structured diagnostic interview for PTSD and psychological testing with the MMPI-2. This recommendation is further bolstered by many studies (e.g. Frueh, Gold, \& de Arellano, 1997; Frueh, Elhai, Gold, et al., 2003) showing high base rates of exaggeration of PTSD on C\&P examinations. The consequences of relying on unstructured interviews was also recently explored by Speroff, Sinnott, Marx, et al., (2011) who found that standardized evaluations (using a structured diagnostic interview for PTSD) produced more complete, consistent, and accurate assessments compared to non-standardized approaches ( $85 \%$ vs $31 \%)$ in C\&P PTSD examinations. Here, the emerging science clearly bears out Worthen and Moering's bold perspective.

No comprehensive forensic psychological or psychiatric assessment is complete without a careful review of collateral and third party information. In this tradition, the third article by Moering provides a detailed guide for reviewing specialized third party collateral information regarding military service. He makes abundantly clear that the assessment of nexus between PTSD or other mental health conditions and military service can be immeasurably aided by an in-depth knowledge of military service treatment and personnel records. With the new "fear easing standard" beginning in July of 2010, C\&P examiners have been asked in PTSD exams if a veteran's stressor is related to "the veteran's fear of hostile military or terrorist activity" (Stressor Determinations for Posttraumatic Stress Disorder, 2010). Because access to PTSD C\&P examinations no longer requires detailed independent corroboration by the Veterans Benefits Administration, Moering points out that review of specialized third party information can provide a crucial basis for corroborating (or disconfirming) a veteran's claim of service connection for PTSD.

In closing, the Special Section on VA C\&P examinations provides a comprehensive perspective for integrating veterans law, the science of psychological injury, psychological assessment, and sound professional practice. The authors are to be congratulated for their serious effort on behalf of psychological injury and the law practice.

\section{References}

Department of Veterans Affairs (2002). Best practice manual for posttraumatic stress disorder (PTSD) compensation and pension examinations. Washington, D.C.: Author.

Frueh, B., Elhai, J., Gold, P., Monnier, J., Magruder, K., Keane, T. \& Arana, G. (2003). Disability compensation seeking among veterans evaluated for posttraumatic stress disorder. Psychiatric Services, 54 (1), 84-91.

Frueh, B. C., Gold, P. B. \& de Arellano, M. A. (1997). Symptom overreporting in combat veterans evaluated for PTSD: Differentiation on the basis of compensation seeking status. Journal of Personality Assessment, 68, 369-384.

Jackson, J. C., Sinnott, P. L., Marx, B. P., Murdoch, M., Sayer, N., Alvarez, J. M., Greevy, R. A., Schnurr, P. P., Friedman, M. J., Shane, A. C., Owen, R. R., Keane \& Speroff, T. M. (2011). Variation in practices and attitudes of clinicians assessing PTSD-related disability among Veterans. Journal of Traumatic Stress, 24(5), 609-613.

Speroff, T., Sinnott, P., Marx, B. P., Owen, R., Jackson, J. C., Greevy, ... \& Schnurr, P.A. (2011). Cluster randomized controlled trial on standardized disability assessment for service-connected posttraumatic stress disorder. Research abstract retrieved from http:// www.hsrd.research.va.gov/meetings/2011/abstract-display.cfm? RecordID $=301$

Stressor Determinations for Posttraumatic Stress Disorder. (2010). 75 Fed. Reg. 39843, (to be codified at 38 C.F.R. pt. 3). 